\title{
SISTEM PENDUKUNG KEPUTUSAN PENERIMAAN ANGGOTA HIMPUNAN MAHASISWA JURUSAN TEKNIK INFORMATIKA DENGAN MENGGUNAKAN METODE ELECTRE (Studi Kasus : Sekolah Tinggi Teknologi Adisutjipto Yogyakarta)
}

\author{
Diana Corry, Yuliani Indrianingsih \\ Jurusan Teknik Informatika \\ Sekolah Tinggi Teknologi Adisutjipto Yogyakarta \\ informatika@stta.ac.id
}

\begin{abstract}
Himpunan Mahasiswa Jurusan (HMJ) is a student organization in the majors at the college level. HMJ Informatics is one of the HMJ on Sekolah Tinggi Teknologi Adisutjipto Yogyakarta. HMJ certainly has a vision and mission, therefore, to realize the vision and mission of the members is required in accordance with the criteria expected. There are several criteria for determining the decisionmaking division members HMJ. Criteria include interest, liveliness, confidence, psychology and CPI (Cumulative Performance Index). To resolve the issue it was made of Decision Support Systems (DSS) recruitment of HMJ division members using the method Elimination and Choice Expressing Reality (ELECTRE). The existences of these systems provide convenience to head of the HMJ to determine HMJ members. The system is built using the programming language Delphi 7 and Oracle databases. Based on calculations by the ELECTRE method obtained ranking prospective members. Taken example, 4 students applying to become a member of HMJ. Calculation shows Gilar Prakoso get ranked first by the number of assessment 4 percentage 80\%, Koko Wiyono second ranked the number 2 percentage $40 \%$ assessment, Linda Putri Susanti third the number of ratings 1 percentage 20\%, and Dini Larasati fourth the number of assessment - 7 the percentage of $0 \%$. The calculations revealed that the results of the manual calculation in accordance with the results of the calculation system and can help the chairman HMJ decision in determining who is eligible to become a member.
\end{abstract}

Keywords: DSS, HMJ, ELECTRE method

\section{Pendahuluan}

Himpunan Mahasiswa Jurusan (HMJ) adalah organisasi mahasiswa di tingkat jurusan di suatu perguruan tinggi. HMJ Teknik Informatika adalah salah satu HMJ pada Sekolah Tinggi Teknologi Adisutjipto Yogyakarta. Suatu HMJ pastinya mempunyai visi dan misi, oleh karena itu untuk mewujudkan visi dan misi tersebut, dibutuhkan anggota-anggota yang berkualitas, bertanggungjawab, disiplin, kreatif, mau berkerja keras agar dapat bekerjasama. Kriteriakriteria tersebut sangat diharapkan dimiliki oleh setiap anggota HMJ, agar HMJ dapat berjalan sesuai dengan visi dan misi, dapat membuat HMJ yang berkualitas, dan dapat melakukan sebuah perubahan dan perbaikan pada waktu mendatang.

Sehubungan dengan hal tersebut, ketua HMJ dituntut untuk dapat melakukan pengambilan keputusan secara cepat dan cermat, untuk menentukan anggota. Sejauh ini mekanisme pengambilan keputusan penerimaan anggota HMJ masih dilakukan secara manual. Oleh karena itu perlu dibangun sebuah sistem pendukung keputusan untuk 
menentukan anggota HMJ Teknik Informatika yang akan membantu penentuan siapa yang layak untuk menjadi anggota.

\section{Kajian Pustaka}

Perbandingan Perangkingan 30 Universitas Di Indonesia Versi WEBOMETRIC. Dengan Hasil Perangkingan Menggunakan Metode ELECTREE Dan Metode VIKOR. Dalam jurnal "Perbandingan Perangkingan 30 Universitas Di Indonesia Versi Webometrics Dengan Hasil Perangkingan Menggunakan Metode ELECTREE Dan Metode Vikor" membahas tentang perbandingan peringkat antara perankingan website universitas di Indonesia dengan menggunakan metode ELECTREE dan Vikor dengan hasil perankingan Webometrics. Data website akademik tersebut diambil dengan menggunakan search engine Google untuk mengetahui visibility, size, rich file, dan scholar. Setelah data diperoleh kemudian dilakukan perhitungan untuk memperoleh hasil perankingan dengan metode ELECTREE dan Vikor (Maria Antonius Dian Wahyu, 2014).

Dalam jurnal "ELECTRE Method" membahas tentang penelitian munculnya 'ELECTRE Family Method'. Penelitian ini telah dilakukan oleh beberapa peneliti terutama Eropa. Tujuannya adalah untuk menyajikan survey metode ELECTRE sejak yang pertama kali dikenalkan oleh Bernard Roy. Jurnal ini menyajikan sejarah singkat metode ELECTRE, fitur utama dari metode ELECTRE, menjelaskan perbedaan ELECTRE menurut tiga masalah utama yaitu outranking, perankingan, dan penyortiran, dan bagaimana metode ELECTRE untuk perangkat lunak dan aplikasi (Jose Figueira, 2003).

Dalam buku "Fuzzy Multi-Attribute Decision Making (Fuzzy MADM)" membahas tentang aplikasi logika fuzzy untuk penyelesaian masalah pengambilan keputusan dalam bentuk Multi-Attribute Decision Making (MADM). Beberapa metode penyelesaian masalah MADM, seperti Simple Additive Weighting Method (SAW), Weighted Product (WP), ELimination and Choice Expressing Reality (ELECTRE), Technique for Order Preference by Similarity to Ideal Solution (TOPSIS) dan Analytic Hierarchy Process (AHP). Buku ini juga membahas tentang aplikasi logika fuzzy untuk penyelesaian masalah GDM, dan metode fuzzy clustering yang dapat digunakan untuk memberikan derajat kepentingan tertentu bagi sub kelompok yang memiliki karakteristik yang sama (Sri Kusumadewi, dkk, 2006.).

\section{Metodologi Penelitian}

\subsection{Sistem Pendukung Keputusan (SPK)}

Desicion Support System (Sistem Pendukung Keputusan) merupakan sistem informasi yang menyediakan informasi, pemodelan, dan pemanipulasian data. Sistem ini digunakan untuk membantu pengambilan keputusan dalam situasi yang semi terstruktur dan situasi yang tidak terstruktur, dimana tak seorang pun tahu secara pasti bagaimana keputusan seharusnya dibuat (Kusrini, 2007). 


\subsection{Metode ELECTRE}

Metode ELECTRE (Elimination Et Choix Traduisant la Realité) atau (ELimination and Choice Expressing Reality) merupakan salah satu metode dalam Multi-kriteria Decision Making (MADM). Metode ELECTRE diperkenalkan oleh Bernard Roy pada tahun 1965. Pada awalnya ELECTRE digunakan dalam pemilihan tindakan terbaik terhadap sampel-sampel tindakan yang diajukan, namun kemudian ELECTRE dikembangkan dalam tiga hal masalah utama : pemilihan, perankingan, dan penyortiran. ELECTRE memiliki beberapa versi yaitu ELECTRE I, ELECTRE II, ELECTRE III, ELECTRE IV, ELECTRE IS DAN ELECTRE TRI.

Terdapat dua bagian penting dalam ELECTRE : pertama, konstruksi dari satu atau beberapa hubungan outranking yang membandingkan secara komprehensif setiap pasang tindakan; kedua, penguraian prosedur yang meneliti rekomendasi yang diperoleh dari fase pertama. Sifat dari rekomendasi tergantung pada jenis masalah yang dihadapi : pemilihan, perankingan atau penyortiran. Langkah-langkah yang dilakukan dalam penyelesaian masalah menggunakan metode ELECTRE adalah sebagai berikut:

1. Normalisasi matrik menggunakan persamaan :

$R_{i j}=\frac{\left(x_{i j}-x_{j}^{\prime}\right)}{\left(x^{*}{ }^{\prime}-x_{j}\right)}$

$R_{i j}=$ Nilai normalisasi alternatif $i$ kriteria $j$

$X_{i j}=$ Nilai data alternatif $i$ kriteria $j$

$X^{*}{ }_{j} \quad=\quad$ Nilai terbaik dalam suatu kriteria

$X_{j}^{\prime}=$ Nilai terjelek dalam satu kriteria

2. Menentukan concordance antar alternatif

$\mathrm{C}\left(\mathrm{i}, \mathrm{i}^{\prime}\right)=\sum_{j} w j$, di mana $R_{i j}>R_{i^{\prime} j}$

Nilai concordance diperoleh dari hasil penjumlahan nilai bobot kriteria dengan syarat nilai $R_{i j}$ lebih besar dari $R_{i^{\prime} j}$.

3. Menentukan discordance antar alternatif

$\mathrm{D}\left(\mathrm{i}, \mathrm{i}^{\prime}\right)=\sum_{j} w j$, di mana $R_{i j}<R_{i^{\prime} j}$

Nilai discordance merupakan kebalikan dari concordance. Nilai discordance diperoleh dari hasil penjumlahan nilai bobot kriteria dengan syarat nilai $R_{i^{\prime} j}$ lebih besar dari $R_{i j}$.

4. Menentukan nilai concordance (C) dan discordance (D) tiap alternatif

$C(i)=\sum_{i^{\prime}=1}^{n} c\left(i, i^{\prime}\right)$,

dan,

$D(i)=\sum_{i^{\prime}=1}^{n} d\left(i, i^{\prime}\right)$,

\subsection{Perancangan Perangkat Lunak}

Dalam penerimaan anggota HMJ, ketua HMJ memerlukan sebuah sistem untuk mempermudah dalam memilih anggota HMJ. Ada beberapa tes yang dilaksanakan pada penerimaan anggota HMJ, diantaranya sebagai berikut:
a. Tes Wawancara
b. Tes Kerjasama
c. Tes Public Speaking
d. Tes Psikologi
e. Indeks Prestasi Kumulatif (IPK) 


\subsubsection{Kriteria Anggota HMJ}

Dalam penerimaan anggota HMJ, diperlukan beberapa kriteria yang penilaiannya didapatkan dari beberapa tes seperti yang telah disebutkan pada analisa sistem. Penilaian pada setiap kriteria menggunakan skala Likert. Skala Likert merupakan metode pengukuran yang di gunakan untuk mengukur sikap, pendapat dan persepsi seseorang atau kelompok orang tentang fenomena sosial (Sugiono, 2012). Kriteria tersebut adalah sebagai berikut:

a. Minat

Penilaian seberapa besar minat calon anggota dinilai dengan angka 0-100. Tingkat nilai kriteria minat yang harus diplih oleh user yaitu:
a. 5 = Sangat Baik karena nilai 85-100
b. $4=$ Baik karena nilai $75-84$
c. 3 = Cukup karena nilai $60-74$
d. 2 = Kurang Baik karena nilai 50-59
e. 1 = Buruk karena nilai 0-49

b. Keaktifan

Penilaian keaktifan calon anggota dinilai dengan angka 0-100. Tingkat nilai kriteria keaktifan yang harus diplih oleh user yaitu:
a. 5 = Sangat Baik karena nilai $85-100$
b. 4 = Baik karena nilai $75-84$
c. 3 = Cukup karena nilai $60-74$
d. 2 = Kurang Baik karena nilai 50-59
e. 1 = Buruk karena nilai 0-49

c. Kepercayaan Diri

Penilaian kepercayaan diri calon anggota dinilai dengan angka 0-100. Tingkat nilai kriteria kepercayaan diri yang harus diplih oleh user yaitu:
a. 5 = Sangat Baik karena nilai 85-100
b. $4=$ Baik karena nilai $75-84$
c. $3=$ Cukup karena nilai $60-74$
d. 2 = Kurang Baik karena nilai 50-59
e. 1 = Buruk karena nilai 0-49

d. Psikologi

Penilaian psikologi calon anggota dinilai dengan angka 0-100. Tingkat nilai kriteria psikologi yang harus diplih oleh user yaitu:
a. 5 = Sangat Baik karena nilai 85-100
b. $4=$ Baik karena nilai $75-84$
c. $3=$ Cukup karena nilai $60-74$
d. 2 = Kurang Baik karena nilai 50-59
e. 1 = Buruk karena nilai 0-49

e. IPK

Penilaian IPK calon anggota dari transkrip nilai. Tingkat nilai kriteria IPK yang harus diplih oleh user yaitu:
a. 5 = Sangat Baik karena IPK 3,5-4,00
b. 4 = Baik karena IPK 3,0-3,49
c. 3 = Cukup karena IPK 2,0-2,99
d. 2 = Kurang Baik karena IPK 1,0-1,99
e. 1 = Buruk karena IPK 0,0-0,99 


\subsubsection{Pemberian Tingkat Kepentingan Setiap Kriteria}

Tingkat kepentingan diberikan untuk membedakan kepentingan setiap kriteria, yang mana dari setiap kriteria ada yang memiliki pengaruh yang sangat banyak terhadap penilaian atau sedikit seperti berikut ini:
a. 1 = Sangat Rendah
b. 2 = Rendah
c. $3=$ Cukup
d. $4=$ Tinggi
e. 5 = Sangat Tinggi

\section{Hasil Dan Pembahasan}

Tujuan dari implementasi sistem adalah untuk dapat mengetahui cara kerja dari suatu sistem yang dijalankan. Selain itu dapat diketahui pula apakah sistem sudah berjalan dengan baik atau tidak. Sistem yang dibuat ini menggunakan bahasa pemrograman Delphi 7 dan database Oracle. Dalam pengujiannya akan dijalankan proses dari Metode ELECTRE, dimana penerapan metode tersebut memiliki tujuan untuk menyeleksi calon anggota HMJ yang sesuai dengan kriteria yang diharapkan.

Sistem yang telah dibuat merupakan penerapan dari teori yang ada, diimplementasikan ke dalam sebuah program dengan menggunakan metode ELECTRE. Sehingga output yang didapatkan tidak jauh berbeda dengan perhitungan manualnya. Berikut merupakan contoh data dalam pengolahan penyeleksian dengan menggunakan metode ELECTRE dengan contoh kasus penerimaan anggota Himpunan Mahasiswa Jurusan Teknik Informatika pada Sekolah Tinggi Teknologi Adisutjipto Yogyakarta.

Diambil contoh, 4 orang mahasiswa yang mendaftarkan diri untuk menjadi anggota HMJ Teknik Informatika. Pada tabel 1 akan disajikan data penilaian setiap mahasiswa untuk masing-masing kriteria.

Tabel 1. Data Penilaian Calon Anggota

\begin{tabular}{|l|c|c|c|c|c|}
\hline & Minat & $\begin{array}{c}\text { Keaktifa } \\
\mathrm{n}\end{array}$ & $\begin{array}{c}\text { Kepercayaan } \\
\text { Diri }\end{array}$ & Psikologi & IPK \\
\hline DINI LARASATI & 4 & 5 & 3 & 3 & 4 \\
\hline $\begin{array}{l}\text { LINDA PUTRI } \\
\text { SUSANTI }\end{array}$ & 5 & 3 & 3 & 4 & 3 \\
\hline KOKO WIYONO & 3 & 4 & 3 & 4 & 4 \\
\hline GILAR PRAKOSO & 5 & 3 & 3 & 2 & 4 \\
\hline
\end{tabular}

Untuk melakukan perhitungan data, diperlukan nilai bobot kriteria. Nilai bobot kriteria ditentukan oleh pengambil keputusan. Data nilai bobot lima kriteria disajikan pada tabel 2.

Tabel 2. Bobot Kriteria

\begin{tabular}{|c|c|c|c|c|c|}
\hline Kriteria & Minat & Keaktifan & $\begin{array}{c}\text { Kepercayaan } \\
\text { Diri }\end{array}$ & Psikologi & IPK \\
\hline Bobot & 5 & 4 & 4 & 3 & 3 \\
\hline
\end{tabular}


Langkah-langkah penyelesaiannya adalah sebagai berikut :

1. Normalisasi Data

Tabel 3. Normalisasi Matriks

\begin{tabular}{|l|c|c|c|c|c|}
\hline & Minat & $\begin{array}{c}\text { Keaktifa } \\
\mathrm{n}\end{array}$ & $\begin{array}{c}\text { Kepercayaan } \\
\text { Diri }\end{array}$ & Psikologi & IPK \\
\hline $\begin{array}{l}\text { DINI } \\
\text { LARASATI }\end{array}$ & 0,5 & 1 & 0 & 0,5 & 1 \\
\hline $\begin{array}{l}\text { LINDA PUTRI } \\
\text { SUSANTI }\end{array}$ & 1 & 0 & 0 & 1 & 0 \\
\hline $\begin{array}{l}\text { KOKO } \\
\text { WIYONO }\end{array}$ & 0 & 0,5 & 0 & 1 & 1 \\
\hline $\begin{array}{l}\text { GILAR } \\
\text { PRAKOSO }\end{array}$ & 1 & 0 & 0 & 0 & 1 \\
\hline
\end{tabular}

2. Menentukan concordance antar alternatif dengan menggunakan rumus 2 .

Tabel 4. Concordance antar alternatif

\begin{tabular}{|l|l|c|}
\hline \multicolumn{1}{|c|}{ Concordance (C) } & \multicolumn{1}{c|}{ Himpunan } & Nilai C \\
\hline C(Dini,Linda) & $\{$ Keaktifan, IPK\} & 7 \\
\hline C(Dini, Koko) & \{Minat, Keaktifan $\}$ & 9 \\
\hline C(Dini, Gilar) & $\{$ Keaktifan, Psikologi\} & 7 \\
\hline C(Linda, Dini) & $\{$ Minat, Psikologi\} & 8 \\
\hline C(Linda,Koko) & $\{$ Minat $\}$ & 5 \\
\hline C(Linda,Gilar) & $\{$ Psikologi $\}$ & 3 \\
\hline C(Koko,Dini) & $\{$ Psikologi $\}$ & 3 \\
\hline C(Koko,Linda) & $\{$ Keaktifan,Psikologi\} & 7 \\
\hline C(Koko,Gilar) & $\{$ Keaktifan,Psikologi\} & 7 \\
\hline C(Gilar,Dini) & $\{$ Minat $\}$ & 5 \\
\hline C(Gilar,Linda) & $\{$ IPK & 3 \\
\hline C(Gilar,Koko) & $\{$ Minat $\}$ & 5 \\
\hline
\end{tabular}

3. Menentukan discordance antar alternatif dengan menggunakan rumus 3.

Tabel 5. Discordance antar alternatif

\begin{tabular}{|c|c|c|}
\hline Discordance (D) & Himpunan & Nilai D \\
\hline D(Dini,Linda) & $\{$ Minat, Psikologi $\}$ & 8 \\
\hline D(Dini, Koko) & $\{$ Psikologi $\}$ & 3 \\
\hline D(Dini, Gilar) & $\{$ Minat $\}$ & 5 \\
\hline $\mathrm{D}$ (Linda, Dini) & $\{$ Keaktifan, IPK $\}$ & 7 \\
\hline $\mathrm{D}$ (Linda,Koko) & $\{$ Keaktifan, IPK $\}$ & 7 \\
\hline D(Linda,Gilar) & $\{$ IPK $\}$ & 3 \\
\hline $\mathrm{D}($ Koko,Dini) & $\{$ Minat, Keaktifan\} & 9 \\
\hline $\mathrm{D}$ (Koko,Linda) & $\{$ Minat $\}$ & 5 \\
\hline $\mathrm{D}$ (Koko,Gilar) & $\{$ Minat $\}$ & 5 \\
\hline D(Gilar,Dini) & $\{$ Keaktifan, Psikologi\} & 7 \\
\hline D(Gilar,Linda) & $\{$ Psikologi\} & 3 \\
\hline D(Gilar,Koko) & $\{$ Keaktifan, Psikologi\} & 7 \\
\hline
\end{tabular}


4. Dari concordance antar alternatif didapatkan matriks concordance seperti pada tabel 6 .

Tabel 6. Matriks Concordance

\begin{tabular}{|l|c|c|c|c|}
\hline & $\begin{array}{c}\text { DINI } \\
\text { LARASATI }\end{array}$ & $\begin{array}{c}\text { LINDA } \\
\text { PUTRI } \\
\text { SUSANTI }\end{array}$ & $\begin{array}{c}\text { KOKO } \\
\text { WIYONO }\end{array}$ & $\begin{array}{c}\text { GILAR } \\
\text { PRAKOSO }\end{array}$ \\
\hline DINI LARASATI & 0 & 7 & 9 & 7 \\
\hline $\begin{array}{l}\text { LINDA PUTRI } \\
\text { SUSANTI }\end{array}$ & 8 & 0 & 5 & 3 \\
\hline KOKO WIYONO & 3 & 7 & 0 & 7 \\
\hline GILAR PRAKOSO & 5 & 3 & 5 & 0 \\
\hline
\end{tabular}

Menentukan nilai concordance $(\mathrm{C})$ dengan menggunakan rumus 4.

$C(i)=\sum_{i=1}^{n} c\left(i, i^{\prime}\right)$,

Contoh

$$
\begin{aligned}
C_{\text {Dini }} & =0+8+3+5 \\
& =16
\end{aligned}
$$

Dari discordance antar alternatif didapatkan matriks discordance seperti pada tabel 7.

Tabel 7. Matriks Discordance

\begin{tabular}{|l|c|c|c|c|}
\hline & $\begin{array}{c}\text { DINI } \\
\text { LARASATI }\end{array}$ & $\begin{array}{c}\text { LINDA } \\
\text { PUTRI } \\
\text { SUSANTI }\end{array}$ & $\begin{array}{c}\text { KOKO } \\
\text { WIYONO }\end{array}$ & $\begin{array}{c}\text { GILAR } \\
\text { PRAKOSO }\end{array}$ \\
\hline DINI LARASATI & 0 & 8 & 3 & 5 \\
\hline $\begin{array}{l}\text { LINDA PUTRI } \\
\text { SUSANTI }\end{array}$ & 7 & 0 & 7 & 3 \\
\hline KOKO WIYONO & 9 & 5 & 0 & 5 \\
\hline $\begin{array}{l}\text { GILAR } \\
\text { PRAKOSO }\end{array}$ & 7 & 3 & 7 & 0 \\
\hline
\end{tabular}

Menentukan nilai discordance (D) dengan menggunakan rumus 5.

$D(i)=\sum_{i}^{n^{\prime}=1} d\left(i, i^{\prime}\right)$,

Contoh :

$$
\begin{aligned}
& D_{\text {Dini }}=0+7+9+7 \\
& =23
\end{aligned}
$$

Melakukan perankingan, alternatif yang memiliki nilai terbesar dari hasil nilai concordance dikurangi nilai discordance akan menempati peringkat pertama. 
Tabel 8. Hasil Perankingan

\begin{tabular}{|l|c|c|c|c|}
\hline Nama & Concordance (C) & Discordance (D) & C-D & Rank \\
\hline GILAR PRAKOSO & 17 & 13 & 4 & 1 \\
\hline KOKO WIYONO & 19 & 17 & 2 & 2 \\
\hline LINDA PUTRI SUSANTI & 17 & 16 & 1 & 3 \\
\hline DINI LARASATI & 16 & 23 & -7 & 4 \\
\hline
\end{tabular}

Untuk total hasil jumlah penilaian dipersentasekan sebesar $100 \%$ sebagai syarat untuk menjadi anggota HMJ dengan nilai maksimum adalah 5 dan nilai minimum adalah 1.

Hasil perhitungan menggunakan metode ELECTRE dari 4 orang mahasiswa yang mendaftarkan diri dengan penilaian 5 kriteria yaitu Minat, Keaktifan, Kepercayaan Diri, Psikologi, dan IPK untuk mendapatkan anggota HMJ Teknik Informatika yang berkualitas maka didapatkan Gilar Prakoso menjadi peringkat pertama dengan jumlah penilaian 4 persentase $80 \%$, Koko Wiyono peringkat kedua dengan jumlah penilaian 2 persentase $40 \%$, Linda Putri Susanti peringkat ketiga dengan jumlah penilaian 1 persentase 20\% dan Dini Larasati peringkat keempat dengan jumlah penilaian -7 persentase $0 \%$.

Dengan inputan data yang sama kemudian diaplikasikan melalui program Sistem Pendukung Keputusan ini, ternyata menghasilkan nilai yang tidak jauh berbeda, dan memperoleh hasil yang sama. Hal itu dapat dilihat pada Gambar 3. Sistem Pendukung Keputusan Penerimaan Anggota HMJ dengan metode ELECTRE ini sudah sesuai dengan perhitungan secara manual. Oleh karena itu dapat disimpulkan bahwa Sistem Pendukung Keputusan Penerimaan Anggota HMJ dengan Metode ELECTRE ini dapat diterapkan untuk mendukung keputusan dalam menentukan penerimaan anggota HMJ.

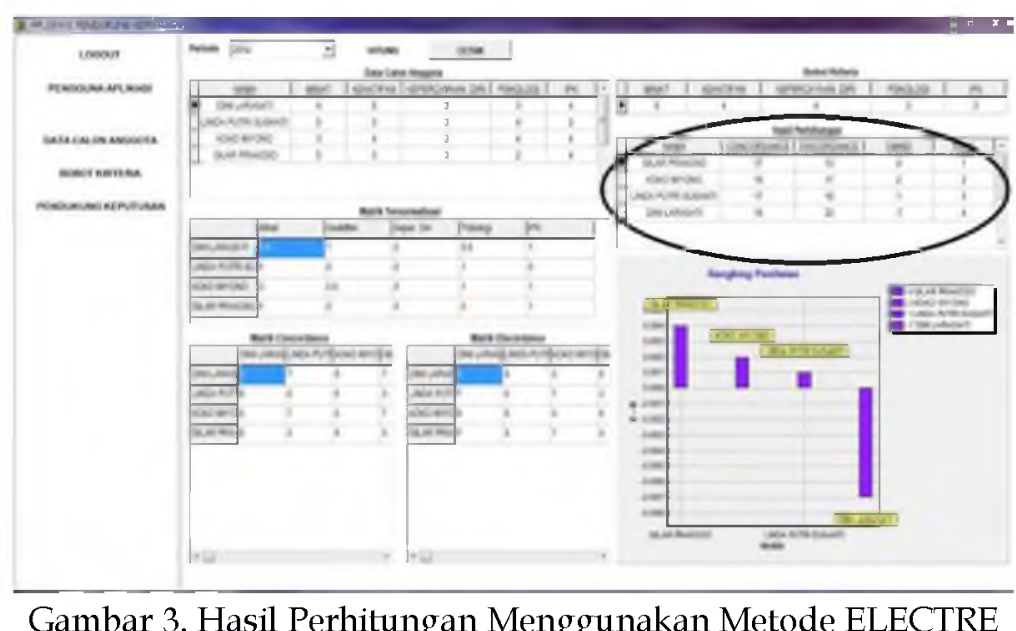

\section{Penutup}

\subsection{Kesimpulan}

Dari hasil pada uji coba yang dilakukan dapat ditarik beberapa kesimpulan sebagai berikut:

1. Aplikasi Sistem Pendukung Keputusan Penerimaan Anggota Himpunan Mahasiswa Jurusan Teknik Informatika dengan menggunakan metode ELECTRE ini sudah berjalan sesuai hasil perhitungan metode ELECTRE yang dilakukan secara manual.

2. Sistem Pendukung Keputusan Penerimaan Anggota Himpunan Mahasiswa Jurusan Teknik Informatika dapat membantu ketua dalam menerima anggota Himpunan 
Mahasiswa Jurusan. Hasil perhitungan sistem didapatkan Gilar Prakoso menjadi peringkat pertama dengan jumlah penilaian 4 persentase $80 \%$, Koko Wiyono peringkat kedua dengan jumlah penilaian 2 persentase $40 \%$, Linda Putri Susanti peringkat ketiga dengan jumlah penilaian 1 persentase 20\% dan Dini Larasati peringkat keempat dengan jumlah penilaian -7 persentase $0 \%$.

\subsection{Saran}

Adapun saran yang diberikan untuk pengembangan tugas akhir ini diantaranya sebagai berikut:

1. Sistem Pendukung Keputusan ini dapat dikembangkan dengan menambahkan metode lainnya, misalnya Logika Fuzzy.

2. Sistem ini dapat dikembangkan menjadi sistem yang berbasis mobile.

\section{Daftar Pustaka}

Jogiyanto. 2005. Analisis dan Desain Sistem Informasi. Yogyakarta : Andi Offset.

Kadir, Abdul. 2005. Pemrograman Database dengan Delphi 7 menggunakan Acces dan ADO. Yogyakarta : Andi Offset.

Karacasu, M. and T. Arslan. 2010. Electre Approach for modeling Public Decision making behavior on Transportation Project Selection Process.

Kusdiantoro. 2010. Analisis Usability Website Akademik Perguruan Tinggi Di Indonesia Menggunakan Metode PROMETHEE, VIKOR, Dan ELECTREE, Yogyakarta:UNY.

Kusrini. 2007. Konsep dan Aplikasi Sistem Pendukung Keputusan, Yogyakarta : Andi Offset.

Kusumadewi, Sri, dkk. 2006. Fuzzy Multi-Attribute Decision Making (Fuzzy MADM). Yogyakarta : Graha Ilmu.

Natividade-Jesus, E., J. Coutinho-Rodrigues, et al. 2007. "A multicriteria decision support system for housing evaluation." Decision Support Systems 43(3): 779-790.

Pamungkas, Maria Antonius Dian Wahyu. 2014. Perbandingan Perangkingan 30 Universitas Di Indonesia Versi WEBOMETRICS Dengan Hasil Perangkingan Menggunakan Metode ELECTREE Dan Metode VIKOR, Yogyakarta: UNY.

Pavlicic, Dubravka M. 2001. Normalisation Affects The Results Of MADM Methods. Yugoslavia Journal of Operations Research 11, Number 2, 251-265.

Tarigan, Prima. 2004. Menguasai Oracle SQL. Jakarta : PT.Elex Media Komputindo. 
Diana Corry, Yuliani Indrianingsih 